\title{
Clinical decisions about patients
}

\author{
Management within multidisciplinary clinical teams
}

\section{J. J. CockBurn, Consultant Psychiatrist, Long Grove Hospital, Epsom, Surrey}

The structure of mental illness services is changing rapidly. Large hospitals are closing or preparing to close and the service will be provided in other ways, partly by smaller units, partly by increased care in the community outside hospital and partly by amalgamations of two or more large hospitals. Smaller units allow closer working relationships with GPs, social workers and other professionals.

The roles and working practices of the professions are changing also. Since the Trethowan Report on Psychological Services, psychologists often receive direct referrals from GPs and many patients thus referred are not seen by consultant psychiatrists. In many districts, community psychiatric nurses are seconded to primary care teams working closely with GPs and away from consultant medical supervision. They may sometimes have more expertise in their particular 'technology' than the doctors.

These changes have led to re-examination of the management structure of the psychiatric service, and in many districts the role of the consultant is being challenged. It is sometimes claimed that all members of the clinical team are of equal importance and there is an attempt to limit the consultant to 'purely medical decisions'. It is also said that the NHS is an 'illness service' at present and should in future concentrate on 'mental health' - a difficult concept to define. Some unit managers have very limited experience of psychiatric illness. These factors could seriously reduce medical influence in planning and lead to a neglect of recent major advances in psychiatric treatment.

In psychiatry there are particular problems. What is 'medical' is often more difficult to define than in surgery and general medicine. Many psychiatric patients have chronic disabilities similar to the disabilities of the elderly and require a multidisciplinary approach provided by a clinical team.

A team has been defined by University of Brunel workers, Rowbottom \& Hey (1978) as a small relatively permanent group of members who meet regularly face to face. Outside the team there will be contact with 'networks' of other workers who meet only occasionally. The psychiatric clinical teamsprovide the specialist treatment and care for the patient in the community which includes hospitals and other treatment facilities. How should these clinical teams be structured and managed to provide the best clinical care?

This was one of several problems addressed by a small care group set up by our Unit General Manager to advise on future mental illness services for the elderly and local authority social services liaison. The care group consisted of two senior nurse managers, two senior social workers, the district head of psychological services and myself - the only doctor. Initial discussions within the group showed that there were conflicting opinions about the interrelations of the professions and the chairman eventually decided to ask for two working papers to facilitate further discussions. I was asked to write a paper entitled 'A Consultant Led Service' and the District Psychologist agreed to produce another paper which, it was orginally suggested, could be entitled 'The Co-operative Approach', a title which was dropped after I objected that a consultant led service was not necessarily unco-operative!

In view of the differing opinions in the care group about the role of the consultant I decided, when writing my discussion paper, to remain on what I thought would be relatively non-controversial 'safe ground' and see how that was received. The paper below was, therefore, limited to the functioning of the multidisciplinary clinical team and the way decisions are reached about the care of the individual patient. The clinical team is the basic unit which provides treatment and care of the patient and the optimal functioning of such teams is extremely important to a health service which is required to put 'patients first'.

\section{Health Service - a consultant led service}

(Produced as a basis for discussion for the Psychogeriatric Care Group in conjunction with another paper by the District Head of Psychological Services describing a model based on non-consultant led services)

(1) The aims of Health Service are to cure illness and, if this is not possible, to reduce disability and alleviate distress. Resources are always limited and both demand and need exceed supply. Enoch Powell, when he was Minister of Health, emphasised that in a free service demand is limited mainly by the waiting 
list, and the DHSS, at the time of the 1974 Reorganisation of the NHS, emphasised the need to allocate resources on the basis of need. The professionals are required to distinguish needs from demands of patients and relatives, and inevitably priority in the allocation of resources must be given to those groups of patients who are most ill and most likely to benefit from medical treatment. The assessment of the likelihood of benefit from treatment is a medical decision and therefore decisions on priorities for health care must continue to be made by consultants after full appropriate multidisciplinary consultation. Decisions are often delegated but responsibility remains that of the consultant.

(2) The Health Service is almost completely funded from central taxation, unlike the Local Authority service which is funded largely from rates levied from local residents. The Secretary of State, therefore, has to exercise authority and control over the spending of this budget and this is delegated through the statutory Health Authorities within the legal framework of the National Health Service Acts. Staff in the Health Service, whether they work in hospitals or in the community, hold contracts with various branches of the Health Service and their salaries are paid out of taxation levied by Central Government.

(3) The Psychiatric Services form part of the Specialist Medical Services to the community and are, of necessity, increasingly multidisciplinary. Service is delivered by specialist multidisciplinary teams which provide both in-patient and out-patient services. Priorities are determined on the basis of clinical need and treatability. When new treatments are developed priorities in the allocation of health service resources often change.

(4) In services for the elderly, priorities must also be allocated to those persons most ill and most likely to respond to medical treatment. Patients should be treated at home if at all possible and should only be admitted as in-patients for good reason. If the patient continues as an out-patient, the role of the clinical team is to provide specialist advice and support to the GP and to the primary teams. Hospital beds for the elderly are always limited and waiting lists are inevitable. It is essential for patients suffering from acute confusional states, where the patient often recovers completely or dies within a matter of days, to be admitted quickly despite the length of the waiting list. It is therefore useful to distinguish between patients who are to be admitted to hospital for medical treatment and those patients admitted principally to provide care for the patient and support for the relatives. Such support is extremely important, as several sociological surveys have shown that for every severely demented patient admitted to any form of residential care there are five to ten times as many similarly incapacitated patients living in the community being cared for principally by their rela- tives. A service must therefore provide effective help for relatives by home support, visits by community psychiatric nurses, day centre and day hospital attendance and by short-term admissions for respite care ('holiday relief').

(5) So far I have described the principal aims of the Health Service and, in particular, services for the elderly. I have been asked to put the case for a consultant led service as opposed to other models which will be proposed by the District Head of Psychological Services. These issues are not just local matters for the DHA as the Health Service exists in a legal framework within which lawyers in the courts determine such issues as responsibility, accountability etc in cases of alleged negligence or in hospital enquiries conducted under Section 70 of the National Health Service Act 1946 (now Section 84 of the NHS Act 1977). Probably the most authoritative legal statement on relationships of different disciplines in the Health Service is contained within the Report of the Committee of Enquiry into Normansfield Hospital which was conducted under Section 70 of the NHS Act 1946.

(6) The Normansfield Hospital enquiry was instituted by the Secretary of State following a strike by nurses at the hospital who were "angry that the Health Authorities had apparently failed to take full notice of their grievance against the consultant psychiatrist in mental sub-normality at the hospital, Dr Terence Lawlor". It followed a period of strained relationships between Dr Lawlor and staff of nursing and other disciplines working within the hospital. The Committee of Enquiry was chaired by $\mathrm{Mr}$ Michael Sherrard QC and included a senior nurse, a consultant psychiatrist, a senior hospital administrator and a lay member. A section of the report is devoted to problems of clinical authority (see paragraphs 234 to 245). The Committee of Enquiry recognised three levels of multidisciplinary management:

(i) "That concerned with the management of services as a whole." (The RTO or District Management Team).

(ii) "The Management of Therapeutic Resources" in which, like the first level, agreement is reached by consensus, and

(iii) "That concerned with the management of the individual patient, (where) the consensus principle no longer operates and the consultant enjoys primacy and authority at the price of medical and legal responsibility.

"In arriving at what should be a detailed and explicit plan of care and therapy for his patient, the consultant must clearly discuss the patient's needs with all the staff who have a proper interest in the particular patient (the therapeutic team); and perhaps the most effective way of doing this is by case conference. 
"He can accept or reject the contribution which is offered by any of those taking part but should do so on a reasoned basis. The consultant must respect the professional competence of the different members of the therapeutic team and although enjoying primacy should not attempt to give instructions as to how a member of a paramedical profession is to exercise his or her professional skill, nor seek to usurp the responsibility of nursing for the establishment of professional standards of care." (para 241). In para 244 the Committee says: "We do not see any conflict between our view and the view expressed by the Royal College of Psychiatrists in their Memorandum on 'The Responsibilities of Consultants in Psychiatry'; which stated inter alia:

'A consultant has the ultimate responsibility and overall authority to diagnose illness and prescribe treatment. This authority may be delegated but the responsibility cannot be abrogated. In view of the high costs and complexity of modern medical treatment, there is a responsibility and duty to be concerned in the administrative processes of the National Health Service and to play an active role in ensuring that resources are used with efficiency and economy.

'The consultant has a direct responsibility to see that the variety of disciplines caring for patients are co-ordinated and used effectively to pursue the major objective of the best treatment for the individual patient and his medical care. This implies leadership of the multi-disciplinary teams dealing with the clinical problems and accepting the responsibility of leadership'.

"Two features seem to us to emerge: first, the responsibility of the consultant is his clinical and legal responsibility; it is not to be equated with power per se. Second, it is the duty of AHAs to implement the care policies of the RHAs ..."

(7) I have quoted the legal opinion published in the Normansfield Enquiry Report in detail not only because it is an opinion of a multidisciplinary Committee chaired by an eminent QC but also because it was written following very lengthy, detailed and costly investigations into the failure of interprofessional relationships within the hospital. The report emphasises the medical and legal responsibility of the consultant and the "primacy and authority" that is associated with this responsibility. It is a fundamental tenet of management that power and responsibility should be equated.

(8) Consultants are appointed after a rigorous medical training leading to postgraduate qualifications and following a competitive interview before an Advisory Appointments Committee procedure in accordance with the NHS Act 1946 . The consultant's training equips him with widely based expertise to help the patient with treatment ranging from ECT and drug treatment to psychotherapy, including behavioural psychotherapy. This enables him, within the multidisciplinary team, to formulate a treatment plan for the individual patient and it is impossible to think of any other discipline that would have the necessary training or qualifications. The consultant's role as leader of the clinical team is not just the view of the lawyers but also of experts in management. Professor Roger Dyson, Director, Health Manpower Review, Keele University, in a recent article encouraging doctors to play a more active role in management, says, "The consultant's inescapable role as team leader in the clinical setting provides many of the skills necessary in the resource management setting, and it is impossible to argue that the consultant does not possess the intellectual capacity for resource management".

Rowbottom \& Hey (1978) in a working paper entitled 'Organisation of Services for the Mentally Ill' analysed the complicated management structure of the Health Service at different levels, including that of the clinical team caring for the individual patient. They consider that the "real problem is who has what may be called primacy in a situation, that is who automatically receives the initial referral (in principle at least, if not by direct communication) and thus automatically assumes prime responsibility for all cases unless specifically transferred" (para 58). They continue, "this last we have found the most difficult and contentious of all issues of multidisciplinary work in the mental health field". There follows a complex discussion on the issues in which they come to no very definite conclusion. They do, however, say that normally in the clinical team only the consultant is likely to be functioning at the third stratum of management ("systematic service provision"); other members of the clinical team will usually be at stratum 2 ("situational response").

(9) Clinical teams require a leader if they are to function effectively. For many patients the dominant technology is medical. The team has to provide an appropriate service for any patient referred to the consultant by the general practitioner, and patient needs vary considerably. At one end of the spectrum of patients' requirements are persons requiring principally medical treatments, e.g. drugs and ECT. "Medical treatment" is, however, very widely defined in the Mental Health Act 1983 (Section 145). Patients suffering from mental disorder may, under certain circumstances following an application based on two medical recommendations, be admitted under the compulsion, to hospital "to receive medical treatment in hospital; and in the case of psychopathic disorder or mental impairment, (on the grounds that) such treatment is likely to alleviate or prevent a deterioration of this condition; and ...." (Mental Health Act, 1983, Section 3(2) (a) and (b). 
The formulation of a "plan of treatment" is the responsibility of the responsible medical officer. Similar principles apply to informal patients in hospital and attending as out-patients.

(10) The leadership role of the consultant in the clinical team implies some accountability of members of other disciplines to the consultant when caring for an individual patient. They therefore have a split accountability which is partly to their line managers. This split accountability can cause difficulty as there may develop 'grey areas' which can lead to disputes. The function of the Health Service is to care for patients and patient care is delivered by the clinical teams. Harmonious working relationships within the clinical teams are very important and there is therefore a necessity for the consultants and the line managers to minimise difficulties.

(11) The consultant team leader must be able to delegate work not only to junior doctors but also to clinical team members of other disciplines but within guidelines formulated by their professional line managers. The delegation to non-medical team members will become even more important in future services when the number of junior doctors is reduced in accordance with the recent medical manpower proposals (DHSS, 1987). This delegation includes the appointment of a 'key worker' when appropriate; the selection will take account of personal characteristics and role specificity.

(12) This discussion concerns only the specialist multidisciplinary clinical teams when the patient is referred to the consultant in the normal way. If the GP refers the patient to an individual member of another discipline (usually psychologist or CPN) the therapist provides a service to the primary health care team and is then accountable to the GP for that patient's care.

(13) In conclusion, the specialist multidisciplinary teams are the units through which the Health Service delivers care to the patient. The management structure is complex but it is important that it is based on the requirements of the patient and the 'technologies' available to help him. The management structure should be explicit and foster good working relationships within the clinical teams without which good patient services cannot be provided.

J. J. COCKBURN

Consultant Psychiatrist

21 September 1987

I had thought my working paper would be noncontroversial; it was not so. There was much disagreement about it within the care group, several members of which stated that they did not accept the legal opinion expressed in the Normansfield Hospital Enquiry Report. Other "differing legal views" were mentioned, but these were not produced and it was eventually decided to ignore the legal aspect, and to discuss the rest of the working paper. There then followed a detailed discussion, paragraph by paragraph, in which about three-quarters of the working paper was rejected by the care group, with me as the only medical member, a minority of one. Soon afterwards the care group ceased to meet and the Unit General Manager was informed that no consensus was possible on this issue.

Within the clinical teams similar problems could occur in consideration of a treatment plan for an individual patient. Usually a consensus occurs readily within the team and there are no difficulties; it is only when there is a failure to reach agreement that difficulties arise. Then the options are limited:

(1) A decision is taken by majority vote - who has the vote and are all votes equal in weight?

(2) One team member makes a decision - if it is not the consultant, who else is appropriate?

(3) No decision is taken, and no treatment plan is formulated.

My working paper was also discussed in the Psychiatric Division which is the 'cog-wheel' Medical Advisory Committee for the Psychiatric Unit. It received unanimous support and the Divisional Chairman wrote to the Unit General Manager stating this. Within the Psychiatric Division the only criticism of the paper was that it was "fine as far as it went", but it did not go far enough. This was inevitable as the paper had been limited to what I considered to be non-controversial discussion in an effort to get it agreed.

If we can accept that the leadership of the clinical team is by the consultant, the specialist clinical team supports the consultant to whom patients are referred by GPs. Such specialist teams should be small and meet regularly and they should have stability of membership. This is particularly important as services are changing from large hospitals to smaller units. The specialist teams should work in in-patient hospital units, day hospitals, mental health centres, out-patient clinics and in the patients' homes. The members will be accountable to the consultant, but a great deal of delegation will inevitably occur.

The consultant has an important supportive role to the team and his effectiveness as a manager will be judged largely by the effectiveness of his clinical team. Professor Kathleen Jones (1985) has described the radical reform movement in Italy 'Psichiatria Democratica' and also developments in the USA. She has stressed the importance of avoiding 'deskilling' of staff such as occurred in Italy, where doctors could be seen scrubbing the floors, and has emphasised the need for the consultant to play a supportive role in the team to help protect the members from 'burn out'. It is important for other professions to work closely with the medical profession. The American Community Mental Health Centre 
Movement 'became anti-medical' and this resulted in a serious deterioration of patient care. Other workers, such as Fagin in the UK, have stressed the importance of Community Mental Health Centres not becoming divorced from the rest of the Mental Health Service. If the clinical teams develop in the way that I have suggested, this danger can be avoided.

The clinical team members are also partly accountable to their line manager, whether they are nurses, social workers, psychologists or other paramedical staff. This split accountability poses an area of potential difficulty between the consultant and the line managers which places some restriction on the freedom of both. It was this area that caused most difficulty in the discussions within the care group where the members were line managers. Like the consultant, the line managers are responsible for ensuring good working relations within the clinical teams, in order to deliver patient care most effectively and perhaps one way of assessing the effectiveness of line managers is by their support to the clinical team members.

Psychologists and community psychiatric nurses are increasingly receiving direct referrals from general practitioners. Under these circumstances they are accountable to the general practitioner and work with the primary health care team. It is desirable that they should be able to receive informal support from members of the specialist clinical teams but this is advisory and must not blur their accountability to the GP. If the patient is referred by the GP to the consultant, the accountability will change if the patient is admitted to hospital, and may be shared between the consultant and the GP if the patient remains an out-patient. In our district, however, the
District Psychologist claims that the members of her department have no accountability to any other discipline, they are accountable only to herself and to the Health Authority.

Where there is reluctance to accept the legal view formulated in the Normansfield Hospital Enquiry Report and a similar view produced by the Wexham Park Hospital Enquiry (1982) District Health Authorities are clearly put in a dilemma. DHSS guidance, perhaps in the form of a circular, is overdue.

\section{References}

DHSS (1972) Management Arrangements for the Reorganised National Health Service. London: HMSO.

_- (1987) Hospital Medical Staffing: Achieving a Balance: Plan for Action. London: Department of Health and Social Security.

Dyson, R. (1987) The medical role in management. The Consultant, 11, 4-5.

FAGIN, L. H. Personal communication.

JONES, KATHLEEN (1985) Lessons from Italy, the USA and York. In Community Mental Health Centres. (ed. T. McAusland). London: King Edward VII Fund.

Report of the Committee of Enquiry into Normansfield Hospital. (1978) Command Paper 7357. London: HMSO.

Rowвоттом, R. \& HeY, A. (1978) Organisation of Service for the Mentally Ill. Working Paper, Brunel Institute of Organisation and Social Studies (B1OSS).

Royal College of Psychiatrists (1977) The responsibilities of consultants in psychiatry. Bulletin of the Royal College of Psychiatrists September, 4-7.

The Report of the Committee of Enquiry into the Breakdown of Working Relationships between Doctors and Nurses in the Psychiatric Unit, Wexham Park Hospital. (1982) Oxford Regional Health Authority.

continued from page 122

\section{Wednesday, 4 January 1989}

We learn at the 9 a.m. meeting that there has still been no use made of our service in the Incident Centre. Neither has the helpline for supporting services been used. There has been little call upon family doctors over the week-end.

There is to be a Memorial Service in Dryfesdale Church, Lockerbie at 2 p.m. The people of Lockerbie

hope this will be a watershed. We decide this is an appropriate time to stop attending the Incident Centre, to remind the senior staff of the supporting services that we are available if necessary, and to arrange to meet the social workers in the near future to discuss longer term plans.

\section{Postscript}

Three comments:

In 14 days the Lockerbie consultant and the two CPNs saw over 100 people. The problems ranged from a few days of irritability and poor sleep to intense guilt feelings and depressive ideas.

We never really established our presence in the Incident Centre. Did anyone suffer through our failure? The American relatives in the main were well served by the social workers. Would the supporting services have benefited from a clearer opportunity to discuss daily events (some of which were quite horrific) with neutral "outsiders" like ourselves, or did they get sufficient support from their peer groups?

I don't think I want to hear that most overused word "counsel" ever again. Let's talk rather about a "sympathetic ear" - an ear which may belong to professionals and non-professionals alike. 